\title{
Gingival Recession Treatment: Surgery and Chemical Compounds
}

\author{
SIMINA CHELARESCU ${ }^{1}$, CRISTINA VAIDA ${ }^{2}$, ALINA ORMENISAN ${ }^{1}$, \\ ELINA TEODORESCU ${ }^{3}$, CRISTIAN OLTEANU ${ }^{4 *}$, JANOS KANTOR $^{5}$, \\ MARIANA PACURAR ${ }^{5}$ \\ ${ }^{1}$ U.M.F.S.T G. E . Palade Tg. Mures, Periodontological Department, 38 Gh. Marinescu Str, 540139, Tg.Mures, Romania \\ ${ }^{2}$ Geppi Mattou Clinic, Marseille Periodontological Department, Marseille, France \\ ${ }^{3}$ U.M.F. Carol Davila, Orthodontic Department, 37 Dionisie Lupu Str., 020021, Bucharest, Romania \\ ${ }^{4}$ U.M.F. Iuliu Haţieganu Cluj-Napoca, Orthodontic Department, 31 Avram Iancu Str, 400089, Cluj-Napoca, Romania \\ ${ }^{5}$ U.M.F.S.T G. E . Palade Tg. Mures, Orthodontic Department, 38 Gh. Marinescu Str., 540139, Tg.Mures, Romania
}

\begin{abstract}
The orthodontic treatment is a favouring factor for the appearance of gingival recession, especially when the teeth are moved toward buccal direction. The purpose of this study is to compare periodontal clinical parameters in patients with gingival recession following fixed orthodontic therapy, treated through two different surgical techniques: free gingival graft (FGG) and connective tissue graft with coronary advanced flap $(C T G+C A F)$, using in both techniques a non-eugenol periodontal dressing. The study is comprised of 12 patients that have previously undertaken fixed orthodontic treatment. 44 sites were treated, 23 of which were treated through free gingival grafts (FGG - with a mean recession of $3.04 \pm 0.2 \mathrm{~mm})$ and 21 through epithelial-connective grafts with a coronary advanced flap (CTG +CAF - with a mean recession of $3.24 \pm 0.24 \mathrm{~mm})$. Sites treated with FGG obtained superior results regarding the width of keratinised tissue (p.0.0006), but recession coverage was superior for CTG+CAF (p.0002). The post-operatory discomfort was diminished by using a non-eugenol periodontal dressing, which also ensured a faster healing time.
\end{abstract}

Keywords: recession, fixed appliances, gingival grafts, orthodontic treatment, flap suture, periodontal dressing

\section{Introduction}

Gingival recession is defined as the displacement of the free gingival margin apical to the cementoenamel junction. Usually, it occurs at a single root surface, most common, at the buccal aspect [1]. The appearance of gingival recession following orthodontic treatment is a controversial study both in the specialty periodontal and in the orthodontic literature, in what regards the intensity and direction of the forces and of gingival biotype [2]. Apart from the unsatisfactory aesthetic effect, the gingival recession leads to dental sensitivity, increases the risk of tooth decay, blocking the maintenance of a satisfactory hygiene. Moreover, gingival recession determines an apical migration of the epithelial attachment with a progressive diminishing of the bone support, which may lead in some situations to loss of teeth [3]. The prevalence of gingival recession during patients undergoing orthodontic treatment is 10-12\% [4].

Gingival recession occurs when teeth are moved outside the envelope of the alveolar bone. Studies suggest that the direction of the orthodontic forces may have an influence on the soft tissue. Proclination of the incisors, through tipping movements, will determine the recession of the buccal margin of the gingiva, as well as loss of epithelial attachment. In these situations, the dehiscence of the alveolar bone is responsible for the recession, produced by the orthodontic movements that have shifted the dental roots outside the cortical plate. In the situation in which the orthodontic movement takes place within the cortical plate, the risk of gingival recession is minimum [4-7].

The anatomy of soft and hard tissues points to the fact that the limit of these movements may be 2$3 \mathrm{~mm}$. Each individual has a different susceptibility to develop gingival recession, thus the orthodontic

\footnotetext{
*email: cristidolteanu@yahoo.com
} 
specialist needs to evaluate carefully the situation case by case. For example, teeth with a thin biotype are exposed to a higher risk of developing gingival recession in the case of buccal movements outside the cortical plate. If inflammation caused by bacterial plaque is present, the risk becomes even higher [4-7].

In regard to the muco-gingival complex susceptible to develop gingival recession following orthodontic treatment, three possible situations exist:

- Pre-existent muco-gingival affections: the patients show gingival recession, frenulum with abnormal insertions, with or without attached keratinized gingiva

- Pre-existent risk: patients show teeth with an uncentered position at the alveolar bone level, with the surrounding bone having a thickness smaller than $1 \mathrm{~mm}$ and a thin gingiva, with or without attached keratinized gingiva and abnormally inserted frenulum

-Planned risk: when the dental movement comes with the risk of developing gingival recession

The gingival recession election treatment is the surgical therapy using gingival grafts in addition with some chemical materials. In the case of pre-existent gingival defects, the gingival grafts are suggested when there is a risk that the gingival recession may progress during or following the orthodontic treatment (poor oral hygiene, lack of attached gingiva, buccal dental movements). When there is no inflammation present, the dental movement predicted will take place in the bone plate and the tooth is accompanied by a large band of keratinized gingiva, the surgical treatment for covering the recession is indicated to take place after the orthodontic treatment. The teeth situated outside the bone plate with traumatic occlusal contacts have a higher risk to exacerbate the muco-gingival defects. There are situations in which, following the elimination of traumatic occlusal contacts, the mucogingival conditions are improving [8].

In the situation of a tooth with muco-gingival defects, without dental malposition, the mucogingival treatment must take place as early as possible, before orthodontic treatment, to prevent any later migrations of the gingiva.

If in the past the pre-orthodontic muco-gingival treatment was aiming for the growth of the apicocoronal dimension of the gingiva, modern concepts aim for their thickness growth in the case of teeth that are susceptible to develop bone dehiscence. Thus, by growing their thickness, the quality of soft periodontal tissues increases, becoming more resistant to trauma and bacterial plaque induced inflammation [9].

The connective tissue graft is indicated in the treatment of singular or multiple gingival recessions. Due to its predictability and its favourable aesthetic results, it is the most commonly used method in the treatment of gingival recessionan. Combined with the coronary repositioned flap, the connective tissue graft is the election method in the treatment of gingival recession. As opposed to the free gingival graft that focuses more on the improvement of tissue quality (growing the keratinized gingiva and improving the thickness of the gingiva), the connective tissue graft is focused more on the gingival aesthetics, achieving a predictable coverage of the gingival recession. The connective tissue graft is capable to induce the keratinization of the adjacent epithelia, but not in a similar manner as the free gingival graft [10].

The aim of this study is to compare clinical periodontal parameters in patients with post fixed orthodontic therapy gingival recession, treated using two different techniques of periodontal surgery: free gingival graft and connective tissue graft applied through a coronary advanced flap in addition with chemical compounds.

\section{Materials and methods}

The study is comprised of 12 patients, out of which 8 are women and 4 men, with ages between 17 and 55 years, that have previously undertaken fixed orthodontic treatment, with MBT technique and metallic brackets of 0.22 inch, following which gingival recession areas have resulted. The patients included in the study belong to the GEPI Mattout Periodontology Clinic in Marseille (France) and to the Orthodontic and Dento-Facial Orthopedics Clinic UMFST Targu Mures (Romania), with a 
complex treatment : orthodontic-surgical and drugs. The total number of gingival recessions was 44 , 23 of which were treated through free gingival grafts (FGG - with a mean recession of $3.04 \pm 0.2 \mathrm{~mm}$ ) and 21 through epithelial-connective grafts with a coronary advanced flap (CTG + CAF - with a mean recession of $3.24 \pm 0.24 \mathrm{~mm}$ ).

\section{Inclusion criteria:}

- Patients with previous fixed orthodontic treatment

- Patients with class I and II Miller recession, with a recession depth of 2-5mm

- Non-smoking patients

- Patients with no systemic affections or muco-gingival surgical history in the recession

\section{Exclusion criteria:}

- Patients without orthodontic treatment

- Patients with general affections

- Patients with class III Miller recession

Prior to the surgical treatment stage, the following clinical examinations took place:

- RD (Recession depth) - measured from the enamel-cemento junction at the central buccal level to the gingival margin level situated most apically

- PD (Pocket depth) - probing depth, measured from the level of the free gingival margin at the central buccal level, to the base of the gingival sulcus

- CAL (clinical attachment level) - measured from the cemento-enamel jonction at the central vestibular level, to the base of the gingival sulcus

- KT (Keratinized tissue) - the fixed gingiva width, measured from the base of the free gingival margin to the JMG

- Plaque index

- $\quad$ BOP (Bleeding on probing) - the bleeding level during probing

All patients received instructions with reference to the correct techniques for an oral hygiene. In cases where necessary, root planning was performed. The surgical intervention was performed only after the plaque index was reduced below 20\%. The coverage percentage of the gingival recession was calculated for each patient as follows: (initial recession - post-treatment recession)/initial recession $\mathrm{x}$ 100

The stages completed in the first technique with free gingival graft were the following: local anaesthesia with Ubistesin 1:200 000, at the level of the donor and receptor bed. The preparation of the receptor bed by a horizontal incision with a nr.15 scalpel blade at the level at which the re-coverage is desired (inter-proximal bone level) and elevation of split thickness flap, followed by the deepithelization of the attached remaining gingiva at 1-2 $\mathrm{mm}$ around the receptor bed. Root planning and root conditioning with citric acid for 2-3 minutes and its water jet removal for 2-3 minutes was performed for teeth with defects. The harvest of the epithelial-connective gingival graft was performed using a nr. 15 scalpel blade, applied perpendicular to the tissue level, at the palatine level in the molarpremolar area, at $2-3 \mathrm{~mm}$ apical from the free gingival margin. Before the total removal of the graft, a suture is placed at its level to facilitate the movement and prevent its fall. The graft was adapted at the level of the recipient bed and was sutured with non-absorbable 4.0 sized polypropylene wires. Horizontal one-knot sutures were performed, completed with vertical sutures suspended around the teeth. Moderate pressure was applied for a few minutes around the defect, followed by its coverage with periodontal dressing (Coe Pack, GC Europe). The periodontal dressing was applied at the palatal level that will follow a healing per secundam. The periodontal dressing is maintained for 15 days in both areas.

For the connective tissue graft applied through a coronary advanced flap: local anaesthesia with Ubistesin 1:200 000, at the donor and receptor bed level. Two divergent releasing incisions were realized toward the apical. Then, elevation of a split thickness flap was performed, at the interdental papillae level, continuing with a full thickness flap at the bone level and finishing with a splitthickness flap apical of muco-gingival junction (MGJ). Root planning of exposed teeth and root 
conditioning for 2-3 minutes with citric acid and its abundant cleaning for another 2-3 minutes. The citric acid: $\mathrm{HOOC}-\mathrm{CH}_{2}-(\mathrm{HOOC}) \mathrm{C}(\mathrm{OH})-\mathrm{CH}_{2}-\mathrm{COOH}$ removes the smear layer on the roots and exposes collagen fibres, promoting connective tissue attachment on the root surface. To harvest the graft, an incision was performed 2-3 mm apical from the gingival margin, with a $\mathrm{nr} 15$ scalpel blade, applied perpendicular to the tissue level, with the other incisions performed underlying to this area. The connective tissue graft was applied at the recession level at the cementoenamel junction, and is sutured with continuous suture at the cervical margin of the tooth with non-absorbable sutures. The flap is sutured medially and distally through vertical mattress suture with non-absorbable sutures. The graft is sutured medially and distally through two vertical mattress sutures. Periodontal dressing is applied at the donor and receptor level. These materials are physical barriers that are placed in the surgical site to protect the healing tissues from the forces produced during mastication, for comfort and close adaptation. We use the most frequent type, which contain zinc oxide and eugenol and other agents, two synthetic pyrimidine compounds (MS-430 and MS-818), which can accelerate angiogenesis.

Post-operatory instructions were identical for all groups in the study: anti-inflammatory treatment (Advil forte $3 \mathrm{x} /$ day), immediately after the intervention is finalized. Patients refrained from tooth brushing in the graft area for 2 weeks and rinsing with chlorhexidine $0.12 \% 2 x$ /day for 2 weeks. After the removal of periodontal dressing, the hygiene was restarted in the graft areas with soft brushes.

\section{Statistical method}

The statistical approach involved two groups of patients treated with different surgical techniques FGG and CTG+CAF. Within each group, we analyzed parameters (R, K, PD) at two different points in time - T0, before the intervention, and T1, 6 month post-intervention. The statistical software used was SPSS, and we deployed both descriptive statistics to understand the distribution of data, and twosample t-tests to calculate statistical significance levels in the different groups.

\section{Results and discussions}

Measurements done at the beginning of the study (R0, K0, PD0) for each type of graft had a similar average with no statistically significant difference. All initial recessions (R0) had dimensions of 2$5 \mathrm{~mm}$, with a similar average between the two lots of patients $(3.04 \mathrm{~mm}$ for FGG and $3.26 \mathrm{~mm}$ for $\mathrm{CTG}+\mathrm{CAF}$ ), as seen in the following Table (Table 1 and 2).

Table 1. Initial and 6 months post-operative periodontal parameters: R0- initial gingival recession, R16 months post-operative recession, K0- initial width of keratinized tissue, K1-6 months post-operative width of keratinized tissue, PD0- initial probing depth, PD1- 6 months post-operative probing depth

\begin{tabular}{|c|c|c|c|c|c|c|c|c|c|c|c|c|}
\hline Patient & tooth & graft & \multicolumn{2}{|c|}{ Recession } & \multicolumn{2}{|c|}{ Root coverage } & \multicolumn{2}{|c|}{ Keratinizes tissue } & \multicolumn{3}{c|}{ Probing depth } \\
\cline { 3 - 14 } & & & R0 & R1 & mm & $\%$ & K0 & K1 & gain & PD0 & PD1 & change \\
\hline 1 & 34 & FGG & 3.00 & 2 & 1 & 33.33 & 0 & 4 & 4 & 2 & 1 & -1 \\
\hline 2 & 35 & FGG & 2.00 & 1 & 1 & 50 & 0 & 3 & 3 & 2 & 1 & -1 \\
\hline & 16 & $\begin{array}{c}\text { CTG+ } \\
\text { CAF }\end{array}$ & 5.00 & 1 & 4 & 80 & 0 & 3 & 3 & 2 & 1 & -1 \\
\hline & 14 & $\begin{array}{c}\text { CTG+ } \\
\text { CAF }\end{array}$ & 5.00 & 1 & 4 & 80 & 0 & 3 & 3 & 1 & 1 & 0 \\
\hline CAF+ & 3.50 & 1.5 & 2 & 57 & 0 & 3 & 3 & 1 & 1 & 0 \\
\hline 3 & 22 & $\begin{array}{c}\text { CTG+ } \\
\text { CAF }\end{array}$ & 2.00 & 0 & 2 & 100 & 1 & 2 & 1 & 1 & 1 & 0 \\
\hline
\end{tabular}




\begin{tabular}{|c|c|c|c|c|c|c|c|c|c|c|c|c|}
\hline & 23 & $\begin{array}{c}\text { CTG+ } \\
\text { CAF }\end{array}$ & 2.50 & 0 & 2.5 & 100 & 2 & 2 & 0 & 2 & 1 & -1 \\
\hline & 24 & $\begin{array}{c}\text { CTG+ } \\
\text { CAF }\end{array}$ & 3.00 & 0 & 3 & 100 & 2 & 2 & 0 & 2 & 1 & -1 \\
\hline \multirow[t]{3}{*}{4} & 22 & $\begin{array}{c}\text { CTG+ } \\
\text { CAF }\end{array}$ & 3.00 & 1 & 2 & 66.66 & 2 & 3 & 1 & 2 & 1 & -1 \\
\hline & 23 & $\begin{array}{l}\text { CTG+ } \\
\text { CAF }\end{array}$ & 4.50 & 0 & 4.5 & 100 & 0 & 2.5 & 2.5 & 1 & 1 & 0 \\
\hline & 24 & $\begin{array}{c}\text { CTG+ } \\
\text { CAF }\end{array}$ & 4.00 & 2 & 2 & 50 & 0 & 2 & 2 & 1 & 1 & 0 \\
\hline \multirow[t]{2}{*}{5} & 23 & $\begin{array}{c}\text { CTG+ } \\
\text { CAF }\end{array}$ & 3.00 & 0 & 3 & 100 & 2 & 5 & 3 & 2 & 1 & -1 \\
\hline & 24 & $\begin{array}{c}\text { CTG+ } \\
\text { CAF }\end{array}$ & 4.00 & 2 & 2 & 50 & 3 & 5 & 2 & 2 & 1 & -1 \\
\hline \multirow[t]{9}{*}{6} & 16 & $\begin{array}{c}\text { CTG+ } \\
\text { CAF }\end{array}$ & 5.00 & 0 & 5 & 100 & 1.5 & 6 & 4.5 & 1 & 1 & 0 \\
\hline & 15 & $\begin{array}{l}\text { CTG+ } \\
\text { CAF }\end{array}$ & 2.00 & 0 & 2 & 100 & 5 & 6 & 1 & 1 & 1 & 0 \\
\hline & 46 & FGG & 4.00 & 2 & 2 & 50 & 3 & 5.5 & 2.5 & 2 & 1 & -1 \\
\hline & 45 & FGG & 4.00 & 3 & 1 & 25 & 2 & 4 & 2 & 1 & 1 & 0 \\
\hline & 42 & FGG & 3.00 & 0 & 3 & 100 & 2.5 & 6.5 & 4 & 2 & 1 & -1 \\
\hline & 41 & FGG & 0.50 & 0 & 0.5 & 100 & 3 & 6.5 & 3.5 & 2 & 1 & -1 \\
\hline & 24 & $\begin{array}{c}\text { CTG+ } \\
\text { CAF }\end{array}$ & 2.00 & 1 & 1 & 50 & 4 & 4 & 0 & 2 & 1 & -1 \\
\hline & 26 & $\begin{array}{c}\text { CTG+ } \\
\text { CAF }\end{array}$ & 5.00 & 2 & 3 & 60 & 2 & 6 & 4 & 1 & 1 & 0 \\
\hline & 27 & $\begin{array}{c}\text { CTG+ } \\
\text { CAF }\end{array}$ & 2.50 & 2 & 0.5 & 20 & 3 & 3 & 0 & 1 & 1 & 0 \\
\hline 7 & 41 & FGG & 3.00 & 0 & 3 & 100 & 2 & 4.5 & 2.5 & 2 & 1 & -1 \\
\hline \multirow[t]{4}{*}{8} & 31 & FGG & 3.50 & 0.5 & 3 & 85.7 & 0 & 5 & 5 & 2 & 1 & -1 \\
\hline & 41 & FGG & 4.00 & 1.5 & 2.5 & 62.5 & 0 & 5 & 5 & 2 & 1 & -1 \\
\hline & 34 & FGG & 5.00 & 4 & 1 & 20 & 0 & 4 & 4 & 2 & 1 & -1 \\
\hline & 35 & FGG & 3.00 & 3 & 0 & 0 & 0 & 3 & 3 & 2 & 1 & -1 \\
\hline \multirow[t]{5}{*}{9} & 44 & FGG & 3.00 & 0 & 3 & 100 & 4 & 7.5 & 3.5 & 2 & 1 & -1 \\
\hline & 33 & FGG & 2.50 & 2.5 & 0 & 0 & 1 & 6.5 & 5.5 & 2 & 1 & -1 \\
\hline & 34 & FGG & 3.00 & 3 & 0 & 0 & 1 & 6.5 & 5.5 & 2 & 1 & -1 \\
\hline & 12 & $\begin{array}{c}\text { CTG+ } \\
\text { CAF }\end{array}$ & 2.00 & 0 & 2 & 100 & 2 & 2 & 0 & 1 & 1 & 0 \\
\hline & 13 & $\begin{array}{c}\text { CTG+ } \\
\text { CAF }\end{array}$ & 3.00 & 0.5 & 2.5 & 83.3 & 2 & 2 & 0 & 1 & 1 & 0 \\
\hline \multirow[t]{5}{*}{10} & 21 & $\begin{array}{c}\text { CTG+ } \\
\text { CAF }\end{array}$ & 3.00 & 0 & 3 & 100 & 1.5 & 2 & 0.5 & 2 & 1 & -1 \\
\hline & 22 & $\begin{array}{l}\text { CTG+ } \\
\text { CAF }\end{array}$ & 2.00 & 0 & 2 & 100 & 2 & 2 & 0 & 2 & 1 & -1 \\
\hline & 23 & $\begin{array}{l}\text { CTG+ } \\
\text { CAF }\end{array}$ & 2.50 & 0 & 2.5 & 100 & 1.5 & 2 & 0.5 & 3.5 & 1 & -2.5 \\
\hline & 31 & FGG & 3.50 & 1 & 2.5 & 71.42 & 0 & 3 & 3 & 1.5 & 1 & -0.5 \\
\hline & 41 & FGG & 3.50 & 1 & 2.5 & 71.42 & 3 & 4 & 1 & 1.5 & 1 & -0.5 \\
\hline
\end{tabular}




\begin{tabular}{|c|c|c|c|c|c|c|c|c|c|c|c|c|}
\hline 11 & 44 & FGG & 2.00 & 1 & 1 & 50 & 2 & 4 & 2 & 1.5 & 1 & -0.5 \\
\hline & 45 & FGG & 2.50 & 1 & 1.5 & 60 & 2 & 4 & 2 & 1.5 & 1 & -0.5 \\
\hline \multirow{2}{*}{12} & 46 & FGG & 2.00 & 1 & 1 & 50 & 2 & 4 & 2 & 1 & 1 & 0 \\
\hline \multirow{2}{*}{} & 44 & FGG & 4.00 & 3 & 1 & 25 & 2 & 2 & 0 & 2 & 1 & -1 \\
\hline \multirow{2}{*}{ Mean } & 34 & FGG & 4.00 & 3 & 1 & 25 & 2 & 9 & 7 & 2 & 1 & -1 \\
\hline
\end{tabular}

Table 2. Averages of all measurements (R, K, PD) in mm at T0 in FGG and CTG+CAF groups

\begin{tabular}{|c|c|c|c|}
\hline Technique & Recession & Keratinization & Depth probing \\
\hline FGG & $3.04 \pm 0.20$ & $1.54 \pm 0.25$ & $1.83 \pm 0.06$ \\
\hline CTG+CAF & $3.26 \pm 0.24$ & $1.74 \pm 0.28$ & $0.093 \pm 0.14$ \\
\hline P value & 0.492 & 0.615 & 0.093 \\
\hline
\end{tabular}

After 6 months from the intervention, both lots obtained a reduction in the gingival recession ( $\mathrm{p}$ 0.002). For the FGG treated patients, the mean coverage was $1.65 \mathrm{~mm}$ and for the CTG+CAF group the mean coverage was $0.67 \mathrm{~mm}$, with a post-surgical recession degree as shown in table 3 . In $17.39 \%$ (4 sites) of the FGG treated recession, a complete coverage of the recession was obtained, while in the case of CTG+CAF treatments, 52.38\% (11 sites) of cases obtained a complete coverage of the recession. With regards to the keratinization degree, both groups of patients had a similar initial average of keratinized gingiva (K0) of $1.54 \mathrm{~mm}$ for FGG and $1.74 \mathrm{~mm}$ for CTG+CAF - with a statistically insignificant difference (p 0.615). After 6 months post-intervention, a statistically significant keratinization level was obtained for FGG treated patients $(5.20 \pm 0.42)$, as compared to the CTG+CAF patients group (3.21 $\pm 0.32 \mathrm{~mm})$ (Table 4).

Table 3. Recession degree in mm after 6 months post-surgery in FGG and CTG+CAF groups

\begin{tabular}{|c|c|c|c|}
\hline Technique & T0 & T1 & P value \\
\hline GGL & $3.04 \pm 0.20$ & $1.65 \pm 0.24$ & $<0.001$ \\
\hline CTG+CAF & $3.26 \pm 0.24$ & $0.66 \pm 0.17$ & \\
\hline P value & 0.492 & 0.002 & \\
\hline
\end{tabular}

Table 4. Keratinization degree in mm after 6 months post-surgery in FGG and CTG+CAF groups

\begin{tabular}{|c|c|c|c|}
\hline Technique & T0 & T1 & P value \\
\hline FGG & $1.54 \pm 0.25$ & $5.20 \pm 0.42$ & 0.001 \\
\hline CTG+CAF & $1.74 \pm 0.28$ & $3.21 \pm 0.32$ & \\
\hline P value & 0.615 & 0.0006 & \\
\hline
\end{tabular}




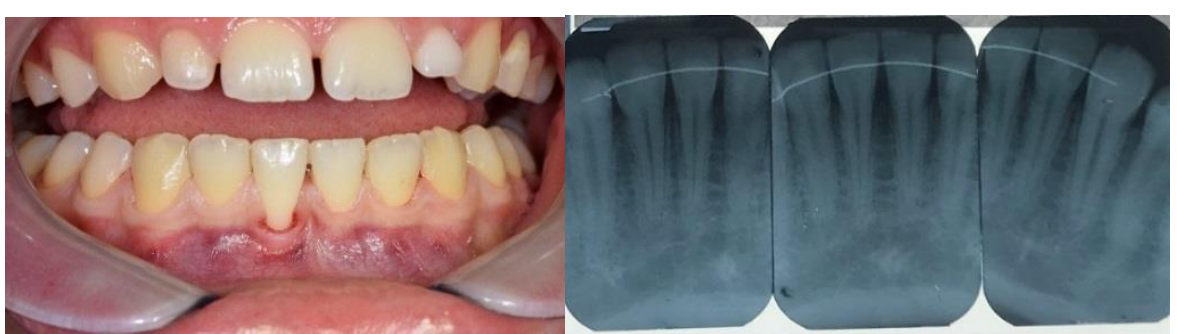

Figure 1a, b. Patient SM 18 years. Clinical and radiographical preoperative view associated with tooth 41

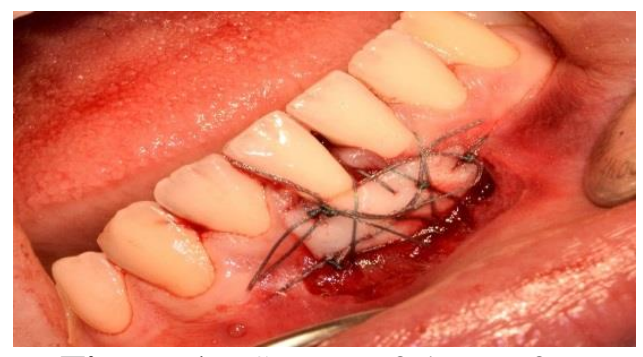

Figure 1c. Suture of the graft at the recipient
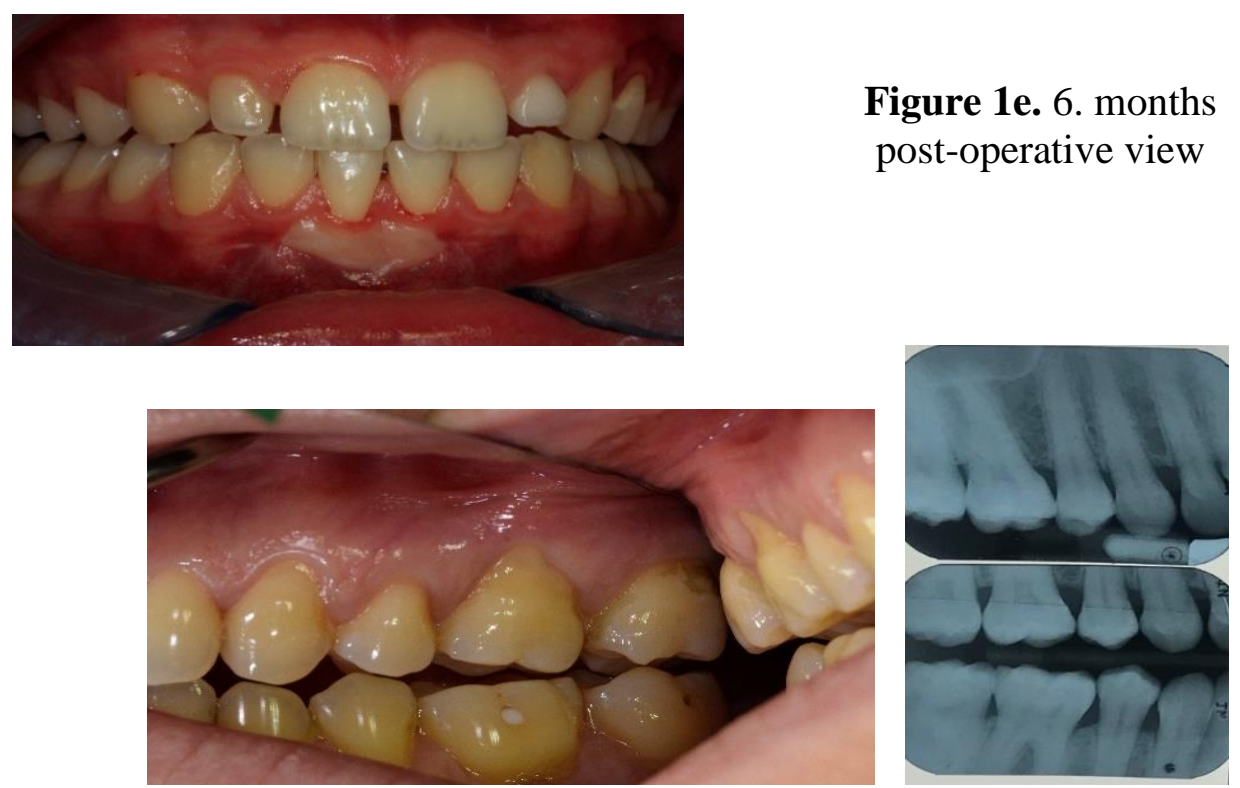

Figure 2a.b. clinical and radiographical pre-operative view of gingival recession associated with tooth 16

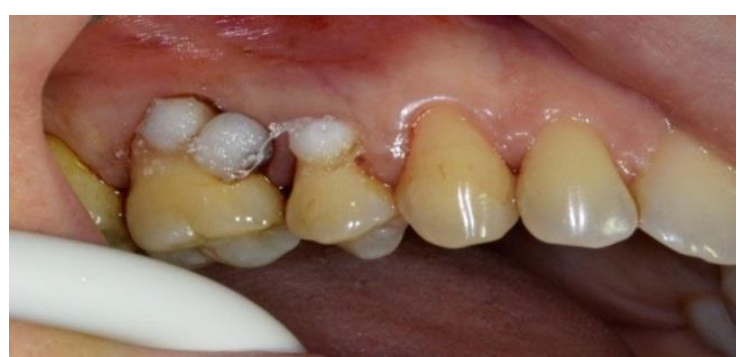

Figure 2c. Root conditioning with citric acid

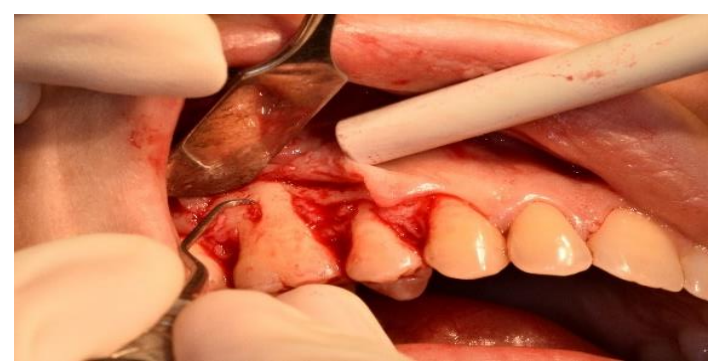

Figure 2d. Elevation of a split-full-split thickness flap and root planning 


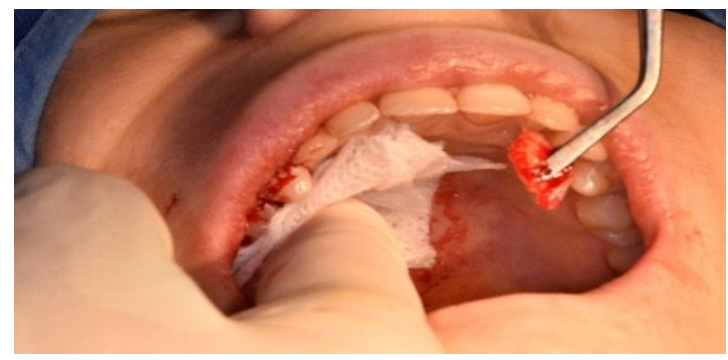

Figure 2e. Harvesting the connective tissue graft from the palatal area

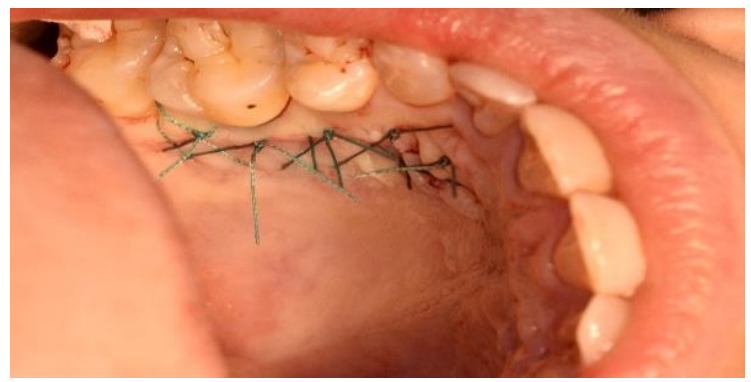

Figure 2g. Donor bed post-operative view

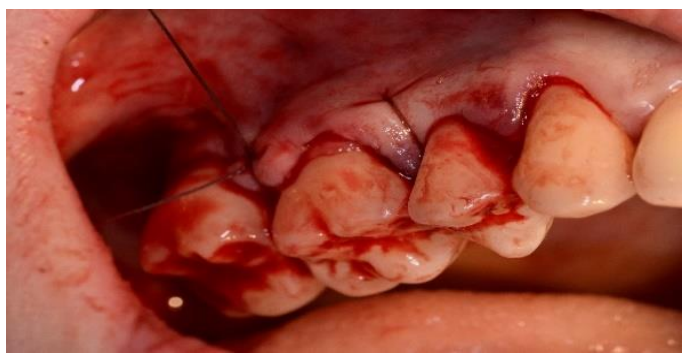

Figure 2f. Graft and flap suture

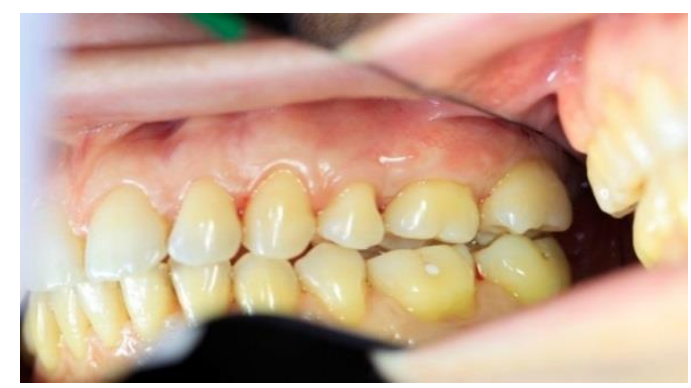

Figure 2h. 6 months post-operative view

In this study we compared the efficiency of the coverage degree of gingival recession through free gingival graft and through the connective tissue graft applied with a coronary advanced flap, for patients who suffered gingival recession following orthodontic treatment. The results regarding the recession degree of the gingival recession are superior for the connective tissue grafts as compared to

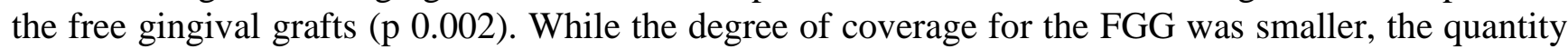
of keratinized gingiva obtained was higher and statistically significant for this lot of patients $(\mathrm{p}$ 0.0006).

Although the connective tissue grafts and the coronary advanced flap represent at the moment the gold standard in the treatment of gingival recessions [11], a particular attention needs to be dedicated to the quantity of the keratinized gingiva obtained, as the maintenance of results for the long term is strongly correlated with this parameter.

The main objective during the harvesting of connective tissue, particularly from the palate, is to obtain the largest quantity of tissue as possible while respecting anatomic limits, but at the same time to minimize the post-operatory discomfort and the possible complications in the healing of the donor area. With regards to the post-operatory discomfort, the studies show that patients who underwent graft collection from the tuberosity signalled a lighter post-operatory discomfort as compared to those who had graft harvested from the palatine area. This is due to the position of the tuberosity which is less susceptible to friction during alimentation [10]. For patients in this study, the post-operatory discomfort was limited through the use of periodontal dressing.

In the literature, the results regarding the coverage degree of the gingival recession through the use of free grafts varies between 40-70\% for class I and II Miller recessions [12]. The lower predictability of these types of grafts compared to the connective tissue grafts is due to multiple factors: insufficient preparation of the receptor area, insufficient root planning, reduced dimension of the interdental papillae, inappropriate graft dimensions or its dehydration, inappropriate stabilization of the graft at the receptor bed level, or trauma at the graft level during the healing period.

Similar results related to the quantity of keratinized gingiva were obtained by Goyal and colab (2018), who reported an average size of keratinized gingiva of $2.92 \mathrm{~mm}$ for free gingival grafts [12]. Carvalho da Silva and co (2004) obtained similar results with regards to the degree of coverage for CTG+CAF, showing a level of $75 \%$ [13]. The connective tissue graft is capable to induce the keratinization of adjacent epithelia, but not in a similar extent as in the case of free gingival graft. 
There are controversies in the literature with regard to the necessary dimension of the keratinized gingiva required to maintain gingival health. Loe and Lang (1972) consider that a strip of $2 \mathrm{~mm}$ of keratinized gingiva is required, whereas other authors (Wennstrom 1990, De Trey 1980) debate this fact, suggesting that gingival health and also be maintained at a width smaller than $1 \mathrm{~mm}$ of the keratinized gingiva [14]. Wennstrom and Lindhe (1983) studied the appearance of gingival inflammation on a canine model, comparing subjects with a large area of keratinized gingiva with subject with a reduced area of keratinized gingiva. As long as the hygiene was maintained, the inflammation was not clinically evident in either of the groups, however 40 days following the interruption of oral hygiene, the subjects with a reduced area of keratinized gingiva showed a much higher degree of inflammation as compared to the other lot. [15]. The keratinization of the gingival tissue can take place only if the graft is composed in most part of collagen fibres and lamina propria. This factor is also influenced by the area of graft collection. In some situations, due to the quality of tissue in regard to the abundance of lamina propria and due to the minimum quantity of fat and glandular tissue, some clinicians prefer to use a connective tissue graft collected from tuberosity, and not from the palatinal area. Some authors (Sulivan Atkins, 1968) consider the fat tissue to be a factor that blocks the revascularization of the graft in the first healing stages [4].

To prevent the gingival recession, some authors recommend the pre-orthodontic gingival augmentation in cases of thin biotypes, when the teeth is to be shifted outside the cortical plate. For teeth with muco-gingival defects, the moment when the orthodontic treatment begins is influenced by the teeth' position on the arcade. The teeth situated in buccal position or bucally inclined may be accompanied by bone dehiscence, brittle soft tissue, being also possibly accompanied by gingival recessions that pre-existed the orthodontic treatment. Their orthodontic recovery, in a lingual/palatal position, will determine growth in the thickness of the gingiva at buccal level and sometimes dehiscence resolution, through bone apposition [4]. In the situation in which these muco-gingival affections appear during the orthodontic treatment, the interruption of the orthodontic treatment is indicated in order to treat the periodontal affections and only after that restart the orthodontic treatment.

A high level of attention needs to be given to frenulum with abnormal insertion, these being favouring factors for the appearance of gingival recession. In order to maintain the results of the surgical treatments for the coverage of gingival recessions, frenulum with abnormal insertion need to be removed when the grafts are performed. If not, in their presence, the oral hygiene is more difficult to maintain, making it difficult to position the dental brush at an appropriate dental level. Both the brushing method indicated by Stillman and the one indicated by Charters assume the application of the dental brush at the level of the free gingival margin. The gingival inflammation is thus maintained by the inadequate removal of the bacterial plaque and the forming of dental calculus. Through the traction exerted by frenulum during mastication, making the penetration of food particles in the gingival sulcus or in the periodontal pocket possible, thus determining the gingival inflammation $[16,1]$.

There is also the frequently encountered situation in which the surgical treatment for coverage of the gingival recession is performed post-orthodontic treatment. The most used techniques for gingival recession coverage are the free gingival graft and the coronary advanced flap, with or without connective tissue graft. The free gingival graft (Atkins and Sullivan, 1968) is indicated particularly to increase the width of keratinized gingiva, but it can also realize full coverage of gingival recessions. The disadvantages of using this type of graft are represented by the possible weak aesthetic results and certain colouristic discrepancies compared to adjacent tissues, or the healing of the tissue with keloid aspect. Their usage is indicated particularly in areas with lower aesthetic demands or in areas with reduced vestibule. However, good results were obtained using this technique in regard to the coverage degree. Holbrook and Ochsenbein obtained a complete recession coverage in $44 \%$ of cases; Miller obtained a coverage of $92.15 \%$ for 79 recessions, with similar results obtained also by Michaelides and Wilson: $96 \%$ recession coverage for 26 recessions from 27 included in the study [17]. 
An important factor in the success of the graft is represented by the conditioning of the radicular surface. A study conducted by Natalia and all (2011) demonstrated the superior efficiency of citric acid in the removal of the smear layer as compared to other substances used with this objective (tetracycline, phosphoric acid, ETA). The citric acid contributes to regeneration of periodontal tissues through: accelerating the healing, inducing the mesenchymal differentiation of cells, efficiently removing bacteria and endotoxins from the root surfaces, accelerating cementogenesis and enlarging the dentinal tubes. By removing the smear layer on the roots, it exposes collagen fibres, promoting connective tissue attachment on the root surface [18].

Post-operative discomfort was diminished by the use of periodontal dressing. Periodontal dressing is considered to be an important factor that contributes to the outcome of the surgical procedure. The periodontal dressing which we used, Coe-Pak, is a Zinc Oxide without Eugenol one, provided in two tubes (the base paste containing Zinc Oxide, oil, gums, lorothidol, and the catalyst paste, containing coconut fatty acids with colophony rosins and chlorothymol). Being an Eugenol free dressing, it does not irritate the tissue, preventing the flap to detach from the root surface, thus promoting a better healing. However, there are some researchers who state that this periodontal dressing can lead to contact allergy and skin dermatitis reactions. This is caused by the rosin, which is among the main components of the dressing (up to 70\%). In vitro conditions, the resin acids promote a dose dependent reaction in fibroblasts and polymorphonuclear leucokytes. The effects are diminished by increasing the zinc concentration [19]. Similar results were obtain by Soheilifar S. who showed that, when using periodontal dressing, patients experienced less pain than those who did not receive periodontal dressing. However, in their study, patients did not present any significant difference between the sites with and without periodontal dressing, regarding bleeding, gingival consistency, or swelling. However, their results were obtained on sites treated for pocket elimination (modified Widman flap). Periodontal dressing is considered to be more efficient on cases treated with grafts [20].

\section{Conclusions}

The two techniques are similar from an operating time and obtained results (recession coverage) point of view. (the aesthetic and functional results are approximately equal )

The connective tissue graft is capable to induce the keratinization of adjacent epithelium, but in a lower extent compared to the epithelial-connective graft.

In regard to the degree of coverage of the gingival recession, the lot of patients treated through $\mathrm{CTG}+\mathrm{CAF}$ obtained superior results $(0.66 \pm 0.17)$ to the group treated with free gingival graft $(1.65 \pm$ $0.24)$.

With regards to the size of the keratinized gingiva, we recommend the treatment with free gingival graft (5.20 \pm 0.42 vs $3.21 \pm 0.32)$.

The post-operatory discomfort was diminished by using periodontal dressing, which also ensured a faster healing time by protecting the wound from mechanical trauma, assuring stability and prevention of site infection.

\section{References}

1.JATI, A.S., FURQUIM, L.Z., CONSOLARO, A., Gingival recession: its causes and types, and the importance of orthodontic treatment, Dental Press J Orthod., 21(3), 2016, 18-29.

2.JOHAL, A., KASTAROS, C., KILIARDIS, S., LEITO, P., ROSA, M., SCULEAN, A., WEILAND, F., ZACHRISSON, B., State of the science on controversial topics: orthodontic therapy and gingival recessions, Prog Orthod., 14(1), 2013, 16.

3.RICHMAN C., Is gingival recession a consequence of an orthodontic tooth size and/or tooth position discrepancy? A paradigm shift, Compend Contin Educ Dent., 31(6), 2010, 1-9.

4.GORBUNKOVA, A., PAGNI, G., BRIZHAK, A., FARRONATO, G., RASPERINI, G., Impact of Orthodontic Treatment on Periodontal Tissues: A Narrative Review of Multidisciplinary Literature. Int J Den., 2016,2016. 
5.BHATSANGE, A., SHENDE, A., DESHMUKH, S., JAPATTI, S., Management of fenestration using bone allograft in conjunction with platet-rich fibrin, J Indian Soc Periodontol., 21(4), 2017, 337 340.

6.TEPEDINO, M., FRANCHI, L., FABBRO, O., CHIMENTI, C., (2018). Post-orthodontic lower incisor inclination and gingival recession - a systematic review, Progr Orthod., 19, 2018, 17.

7.COSKUN, I., KAYA, B., Appraisal of the relationship between tooth inclination, dehiscence, fenestration, and sagittal skeletal pattern with cone beam computed tomography, Angle Orthodontist., 89(4), 2019, 544

8.EVANS M., TANNA, N.K., CHUNG, C.H., 3D guided comprehensive approach to mucogingival problems in orthodontics, Semin Orthod., 22(1), 2016, 52-63.

9.HOLMES, H.D., TENNANT, M, GOONEWARDENE, M.S., Augmentation of faciolingual gingival dimension with free connective tissue grafts before labial orthodontic tooth movement: An experimental study with a canine model, Am J Orthod Dentofacial Orthop., 127(5), 2005, 562-72.

10.TAVELLI, L., BRATOOCHI, S., GREENWELL, H., WANG, H.L., Is a soft tissue graft harvested from the maxillary tuberosity-The approach of choice in an isolated site? J Periodontol., 90(8), 2019, 821-825.

11.BELLVER-FERNÁNDEZ， R., MARTÍNEZ-RODRIGUEZ， A.M., GIOIA-PALAVECINO, C., CAFFESSE, R.G., PEÑARROCHA, M., Surgical treatment of localized gingival recession using coronally advanced flaps with or without subepithelial connective tissue graft, Med Oral Patol Oral Cir Bucal., 21(2), 2016, e222-e22.

12.GOYAL, M., DEV GUPTA, N., GUPTA, N., CHAWLA, K., Free gingival graft as a single step procedure for treatment of mandibular Miller class I and II recession defects, WJPS., 8(1), 2019, 1217.

13.DA SILVA, R.C., JOLY, J.C., DE LIMA, A.F., TATAKIS, D.N., Root coverage using the coronally positioned flap with /without a subepithelial connective tissue graft, J Periodontol.,75(3), 2004, 413-419.

14.PADMINI, H., KRANTHI, R., HOE, Z.Y., TEH, Y.J., TING, C.J., Correlation between width of attached gingiva, depth of the vestibule on gingival health and oral hygiene maintenance in Malaysian young adults, JCDR., 12(11), 2018, 39-44.

15.ZUHR, O., HURZELER, M,. Plastic-esthetic periodontal and implant surgery, Quintessence publishing, UK, 2012, 31-32.

16.ANAHITA, P., THOMAS, B., AMITHA, R., Management of an aberrant mandibular buccal frenulum- A case report. J Dental Sci., 3(1), 2018, 000158.

17.DEO, SD., SHETTY, S.H., KULlOLI, A., CHAVAN, R., LIGADE, S., DHARMARAJAN, D., Efficacy of free gingival graft in the treatment of Miller class I and class II localized gingival recession: A systematic review, J. Indian. Soc Periodontol., 23(2), 2019, 93-99.

18.BHASIN, M.T., BHASIN, P., SHEWALE, A., BHATIA, N., KHULLER, N., Current trends in root conditioning agents, JPMCP., 3(1), 2016, 11-21.

19.KADKHODAZADEH, M., BAGHANI, Z., TORSHABI, M., BASIRAT, B., In vitro comparison of biological effects of Coe-Pak and Reso-Pac periodontal dressing, J Oral Maxillofac Res., 8(1), 2017, e3.

20.SOHEILIFAR, S., BIDGOLI, M., FARADMAL, J., SOHEILIFAR, S., Effect of periodontal dressing on wound healing and patient satisfaction following periodontal flap surgery, J Dent (Tehran)., 12(2), 2015, 151-156.

Manuscript received: 6.02.2020 